\title{
Nano-level management of calcium silicate- hydrate nanoparticles structure formation during portland cement hydration process
}

\author{
Alexander Guryanov ${ }^{1, *}$, Vyacheslav Kozlov ${ }^{1}$, and Yulia Sidorenko ${ }^{1}$ \\ ${ }^{1}$ Samara State Technical University, Academy of Architecture and Civil Engineering, \\ Molodogvardeyskaya St., 194, Samara, 443001, Russia
}

\begin{abstract}
Cement-containing building materials durability depends both on the original clinker composition and on the structure of hydrated portland cement compositions on micro and nanoscales. To calculate structural parameters of silicate-hydrate calcium nanoparticles during portland cement hydration process, the researchers applied the method of small-angle neutron scattering which included distribution of nanoparticles in size, medium nanoparticles radius, fractal dimension. Modifying nanoparticles blending with portland cement composition affects structural parameters of silicate-hydrate calcium nanoparticles. The authors used complex modifying nanoparticles in this study. Nanoparticle composition included a component that served as a filler and a chemically active component that was used as a modifier. The first component was a mixture of alpha oxide aluminum, gamma oxide aluminum and carbonate sludge. The second component presented a mixture of alumoalkaline sludge with alumocalcite sludge. These sludges were of technogenic origin. The research showed that application of complex nanoagents made it possible to control process of silicate-hydrate calcium nanoparticles structure formation, and, as the result, to influence durability of cement stone.
\end{abstract}

\section{Introduction}

At hydration of portland cement clinker the composite gel framework of calcium silicatehydrate (C-S-H) nanoparticles is formed $[1,2]$. Structural parameters of C-S-H nanoparticles and a cement matrix, affect properties of the formed cement stone [3,4]. First of all on its durability and longevity which, in turn, is bound to water resistance, frost resistance and rust resistance of material [5-7].

The given properties of cement-containing building materials can be obtained, using various additives (excipients, modifiers) which have both simulated (ultradispersible powders), and technogenic (slimes, slags, etc.) origin [5-7]. The additives affect material structure formation on a micro- and nanolevel in the course of hydration of the initial portland cement clinker and, thereby, influence operational properties of the turning-out materials [8-11]. Most vividly it is shown if in additives there is a nanodispersible

* Corresponding author: gurjanovam@mail.ru 
component. Such additives according to idiosyncrasies of their influence on properties of the turning-out building materials can be defined as nanoadditives or nanomaterials.

In the sense of effect nanoadditives are divided into nanofillers (for example, alpha oxide aluminum, gamma oxide aluminum and carbonate sludge) or gel-forming ones (for example, alumoalkaline sludge with alumocalcite sludge). Sludges are a product of technogenic origin, dispersion and adsorption; they are a result of hashing, settling and coagulation of solids formed of the oversaturated solution of sewage as a result of processes of chemical reactions in the process of water cleaning or softening at metal working, oil processing, thermal power plants. Sludges are suspension which is characterized by stability of structure, uniformity and sufficient constancy of structure [12]. Sludges formation conditions correspond to sol-gel technology, while a nanodispersible component allows to refer them to nanotechnogenic raw materials.

In this work with the help of a method of small-angle neutron scattering (SANS) the research of formation of structure of C-S-H nanoparticles of the hydrated portland cement compositions modified by the complex nanoadditives consisting of components of simulated (nanopowders of alpha oxide aluminum, gamma oxide aluminum) and technogenic origin (carbonate, alumoalkaline and alumocalcite sludges). Structural parameters of C-S-H nanoparticles determined. It is shown that the combination of nanoadditives having various focus of action can influence the process of the structure formation of $\mathrm{C}-\mathrm{S}-\mathrm{H}$ nanoparticles of portland cement compositions in the hydration process.

\section{Materials and methods}

To define structural parameters of C-S-H nanoparticles, in the range of $1 \mathrm{~nm}$ to $100 \mathrm{~nm}$, it is possible to use a method of SANS [13]. This method is applicable to study nanoobjects of various physical origin; that is bound to the dependence of SANS intensity on a diffusion property of inhomogeneities in the substance structure and contrast on phase boundaries. Moreover, it is applicable to define structural parameters of hydrated cement compositions [14-16].

The intensity of SANS $I(q)$ contains the information about the outer region of the atom of the scattering particle and depends on the neutron momentum transfer

$$
q=\frac{4 \pi}{\lambda} \sin \frac{\theta}{2}
$$

where $\theta$ is the of neutron scattering.

When performing a condition of $q R_{c}<1$ (Guinier mode) the intensity of small-angle scattering $I(q)$ is defined by the particle size and the form of the scattering particles or inhomogeneities:

$$
I(q)=I(0) \exp \left(-\frac{R_{g}^{2} q^{2}}{3}\right),
$$

where $R_{g}$ is the particle radius of gyration.

Due to the experimental datas on small-angle scattering in the Guinier regime it is possible to estimate the particles gyration radius $R_{g}$ and their size $R_{c}$.

When performing a condition of $q R_{c}>1$ (Porod regime) for intensities of small-angle scattering the exponential law from the neutron momentum transfer is in action:

$$
I(q) \propto q^{-n} \text {. }
$$

The exponent deviation from the Porod asymptotics $(n=4)$ indicates fractal properties of the disseminating objects and allows to define their fractal dimension. In case of volume or mass fractals the exponent coincides with fractal dimension of $n=D_{V}$ and accepts value 
from the interval $1<D_{V}<3$. In case of scattering by the objects having a fractal surface, fractal dimension $D_{S}=6-n$ also accepts value from the interval $2<D_{S}<3$. The exponent corresponding to this case is in the interval $3<n<4$.

It follows from the formula (2) that it is possible to determine belonging of the scattering objects to a particular type of the fractal (volume or surface) by an inclination of straight sections of SANS dependences, constructed in a double logarithmic scale, and the size of the fractal dimension [17-19].

For unequigranular systems, according to the small-angle scattering, it is possible to restitute a cumulative distribution function of scattering objects by means of $G(R)$, proceeding from ranges of pair correlations of $\chi(R)$ received through of Fourier conversion data for scattering sections. These functions are bound to particles form and describe quantitatively a set of the pieces connecting particle volume elements, and they also depend on inhomogeneities distribution within particles. The cumulative distribution function by means of $G(R)$ is the following:

$$
G(R)=R^{2} \gamma(R)=\frac{1}{2 \pi^{2}} R^{2} \int \frac{d \sigma(q)}{d \Omega} \frac{\sin (q R)}{q R} q^{2} d q .
$$

The function $G(R)$ shows whether there are particles of this radius $R$ in the material under study.

Data interpretation of SANS was carried out by means of the program complex ATSAS 2.8.0 [20,21].

Ranges of SANS intensities were measured by samples of portland cement compositions in the Petersburg Nuclear Physics Institute (Gatchina) by means of a diffractometer "Membrana-2" set on the WWR-M reactor. The wavelength of neutrons was equal to $\lambda=0,3 \mathrm{~nm}$ with a width of the line $\Delta \lambda / \lambda=0,25$. The range of recorded resilient transferred neutron impulses $q$ varied from $0,03 \mathrm{~nm}^{-1}$ to $0,8 \mathrm{~nm}^{-1}$. The neutrons scattered by samples were registered in the range of corners $\theta= \pm 0,017 \mathrm{rad}$. The detector consisted of forty-one ${ }^{3} \mathrm{He}$-detectors. The beam intensity on a sample was measured by means of two detectors (monitors) installed in front of the sample above and below the axis of a neutron bunch.

The samples were located in a target device representing a cavity in a cadmium plate. Its volume is equal to $0,52 \mathrm{~cm}^{3}$. The sample layer thickness was equal to the cadmium plate thickness $d_{S}=2 \mathrm{~mm}$. with this thickness of the samples the transmittance (transmission coefficient) of a bunch of neutrons for different samples was $T=0,4-0,9$.

The experimental data were normalized on indications of monitors and the size of transmission. A background subtraction and also that of a contribution of the neutrons which passed through a dispersionless sample were carried out. The received distributions of intensities of scattering $I_{S}(q)$ were normalized further into the distributions of intensities of scattering $I_{S T}(q)$ received under similar conditions by a standard sample which is a layer of light water of $d_{S T}=1 \mathrm{~mm}$ thickness. Differential sections of scattering of samples of portland cement compositions per $1 \mathrm{~cm}^{3}$ of volume of an sample in absolute units were calculated by a formula

$$
\frac{d \sigma(q)}{d \Omega}=\frac{I_{S}(q)}{I_{S T}(q)} \frac{d_{S T}}{d_{S}} \frac{d \sigma_{S T}}{d \Omega} .
$$

From the received sections of scattering of neutrons of Fourier transformation (4) distributions of the scattering objects in an approximation of the homogeneous spheres were restored.

While fitting the experimental data the maximal radius of the scattering objects ranging from 50 up to $100 \mathrm{~nm}$ varied $[20,21]$. With the value of the maximal radius equal to $50 \mathrm{~nm}$ the experimental points corresponding to the minimum transferred neutron impulses were not described. With the value of the maximal radius equal to $100 \mathrm{~nm}$ the points 
corresponding to the maximal transferred impulses were not described. The description of data of scattering was correct enough if the maximal size of the scattering areas was chosen equal to about $80 \mathrm{~nm}$. Along with it the average radius of the scattering objects for the studied samples of portland cement compositions was ranging from $30 \mathrm{~nm}$ up to $65 \mathrm{~nm}$.

Samples were produced on the basis of straight portland cement D0-500. During hydration process of the portland cement $3 \div 5 \%$ of nanoadditives were blended these were nanopowders $\alpha-\mathrm{Al}_{2} \mathrm{O}_{3}$ and $\gamma-\mathrm{Al}_{2} \mathrm{O}_{3}$, carbonate, alumoalkaline or alumocalcite sludges. The Nanopowder $\alpha-\mathrm{Al}_{2} \mathrm{O}_{3}$ was characterized by an average particle size of $80 \mathrm{~nm}$ with a specific surface area not less than $10 \mathrm{~m}^{2} / \mathrm{g}$. The nanopowder $\gamma-\mathrm{Al}_{2} \mathrm{O}_{3}$ had an average particle size of $20 \mathrm{~nm}$ and a specific surface area not less than $160 \mathrm{~m}^{2} / \mathrm{g}$. The structure of the sludges used in this work is represented in Table 1.

Table 1. Mineral structure of sludges.

\begin{tabular}{|c|c|c|c|c|c|c|}
\hline Sludge sample & $\begin{array}{c}\mathbf{A l}_{2} \mathbf{O}_{\mathbf{3}} \\
{[\mathbf{\%}]}\end{array}$ & $\begin{array}{c}\mathbf{C a O} \\
{[\%]}\end{array}$ & $\begin{array}{c}\mathbf{M g O} \\
{[\%]}\end{array}$ & $\begin{array}{c}\mathbf{F e}_{2} \mathbf{O}_{3} \\
{[\%]}\end{array}$ & $\begin{array}{c}\mathbf{S i O}_{2} \\
{[\%]}\end{array}$ & $\begin{array}{c}\text { Losses during } \\
\text { steaming [\%] }\end{array}$ \\
\hline Carbonate & 10 & 43 & 6 & 2 & 4 & 35 \\
\hline Alumoalkaline & 52 & 2 & 2 & 3 & 1 & 40 \\
\hline Alumocalcite & 28 & 16 & 4 & 6 & 2 & 44 \\
\hline
\end{tabular}

Water-cement ratio was ranging from 0,25 to 0,30 . When sludges represented a suspension with a high content of water the water-cement ratio decreased to value $0,18-$ 0,24 .

The measurement of intensities with SANS samples was taken after a day, seven, fourteen and twenty eight days of portland cement mixing. According to the schedules of intensities of neutron scattering the following calculations were carried out: average radii of the scattering objects (C-S-H nanoparticles) $R_{c}$ were determined by a formula (2), their fractal dimensions were determined by a formula (3), by a formula (4) differential sections of scattering were found out and by a formula (5) cumulative distribution functions by distances of scattering objects were determined.

\section{Results}

The structure of samples of the studied portland cement compositions is brought in Table 2 . For all samples the exponential law of intensity of scattering from the transferred neutron impulse according to a formula (2) was observed. As an example, graphs of intensities of neutron scattering of two samples number 8 and 10 for the 28th day after mixing are provided on Figure 1. The sample 8 is portland cement composition with additive of carbonate sludge of 3\% and alumoalkaline sludge of 3\%. A sample 10 is a portland cement composition with $\gamma-\mathrm{Al}_{2} \mathrm{O}_{3}$ of $3 \%$ and alumokalcite sludge of $3 \%$.

Figure 2 represents graphs of cumulative distribution functions of the scattering objects (C-S-H nanoparticles) of $\mathrm{R}_{\mathrm{c}}$ calculated by distances by the formula (5) for Samples 8 and 10.

The description of the studied samples, the calculated values of fractal dimension of $D_{S}$, the average $R_{c}$ size of nanoparticles C-S-H are provided in Table 2. In all samples the added same sludges had an identical chemical composition. The average size $R_{c}$ of nanoparticles $\mathrm{C}-\mathrm{S}-\mathrm{H}$ was calculated after 28 days after cement compositions mixing. 


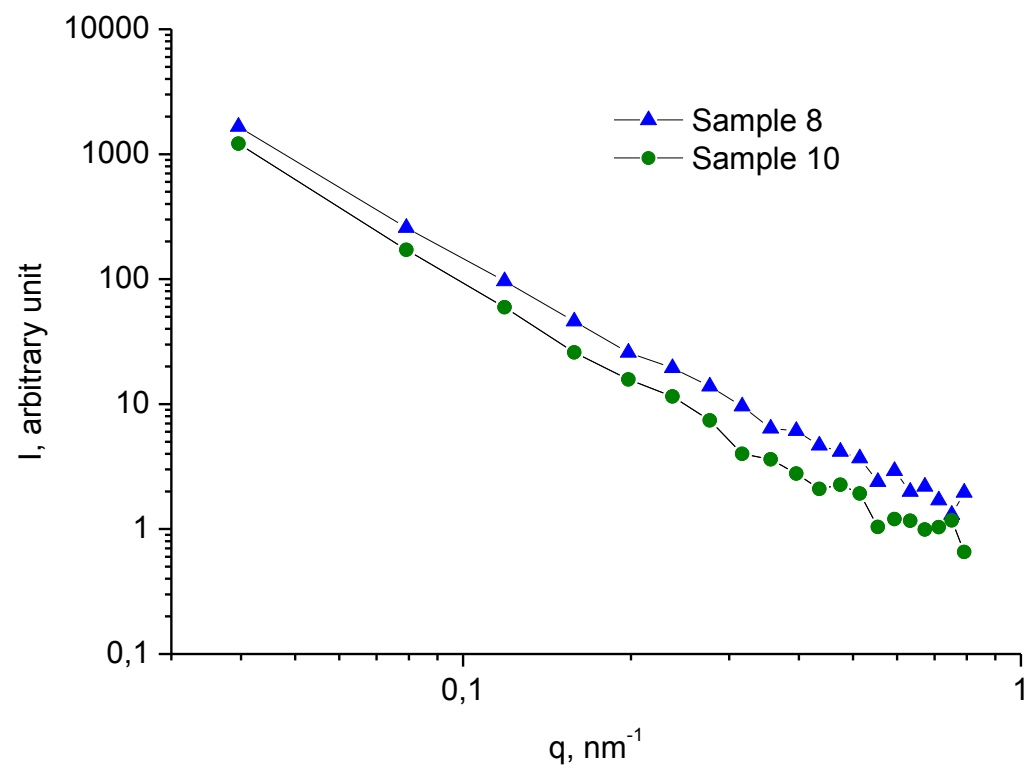

Fig. 1. The experimental ranges of SANS intensities of samples of portland cement compositions. Sample 8 is a cement with additive of carbonate sludge of $3 \%$ and alumocalcite sludge of $3 \%$;; Sample 10 - cement with $\gamma-\mathrm{Al}_{2} \mathrm{O}_{3}$ additive of $3 \%$ and alumocalcite sludge of $3 \%$.

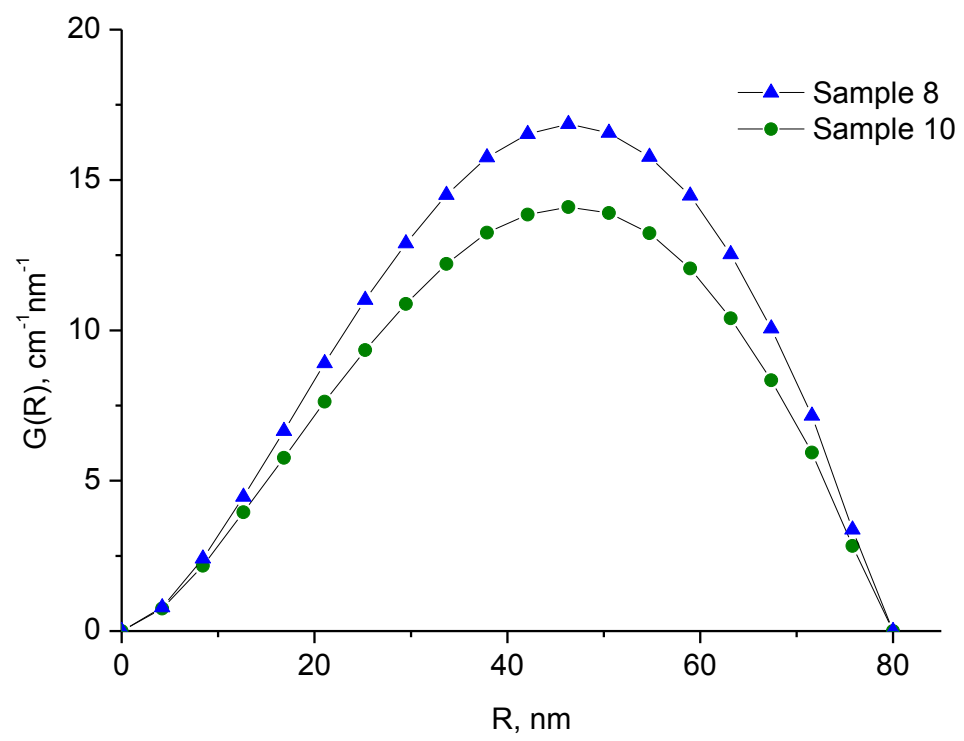

Fig. 2. Cumulative distribution functions of scattering objects by distances of samples of portland cement compositions. . Sample 8 is a cement with additive of carbonate sludge of $3 \%$ and alumocalcite sludge of 3\%.; Sample 10 - cement with $\gamma-\mathrm{Al}_{2} \mathrm{O}_{3}$ additive of $3 \%$ and alumocalcite sludge of $3 \%$. 
Table 2. Structural parameters of samples of portland cement compositions.

\begin{tabular}{|c|c|c|c|c|c|c|}
\hline $\begin{array}{l}\text { Sample } \\
\text { number }\end{array}$ & $\begin{array}{c}\text { Additive type } \\
\text { (sludge)/[\%] }\end{array}$ & $\begin{array}{c}D_{S}, \\
1 \text { day }\end{array}$ & $\begin{array}{c}D_{S} \\
7 \text { days }\end{array}$ & $\begin{array}{c}D_{S} \\
14 \text { days }\end{array}$ & $\begin{array}{c}D_{S} \\
28 \text { days }\end{array}$ & $\begin{array}{l}\boldsymbol{R}_{c}, \\
\mathrm{~nm}\end{array}$ \\
\hline 1 & - & 2,31 & 2,35 & 2,39 & 2,49 & 65 \\
\hline 2 & Carbonate / 5,0 & 2,35 & 2,40 & 2,52 & 2,55 & 60 \\
\hline 3 & Alumoalkaline / 4,5 & 2,44 & 2,50 & 2,62 & 2,76 & 42 \\
\hline 4 & Alumocalcite / 4,5 & 2,42 & 2,44 & 2,48 & 2,62 & 45 \\
\hline 5 & $\gamma-\mathrm{Al}_{2} \mathrm{O}_{3} / 5,0$ & 2,40 & 2,50 & 2,58 & 2,60 & 48 \\
\hline 6 & $\alpha-\mathrm{Al}_{2} \mathrm{O}_{3} / 5,0$ & 2,30 & 2,35 & 2,36 & 2,48 & 52 \\
\hline 7 & $\begin{array}{c}\text { Carbonate } / 3,0+ \\
\text { alumoalkaline / 3,0 }\end{array}$ & 2,40 & 2,48 & 2,56 & 2,62 & 52 \\
\hline 8 & $\begin{array}{l}\text { Carbonate / 3,0+ } \\
\text { alumocalcite / 3,0 }\end{array}$ & 2,44 & 2,46 & 2,52 & 2,66 & 47 \\
\hline 9 & $\begin{array}{c}\gamma-\mathrm{Al}_{2} \mathrm{O}_{3} / 3,0+ \\
\text { alumoalkaline / 3,0 }\end{array}$ & 2,41 & 2,52 & 2,62 & 2,68 & 43 \\
\hline 10 & $\begin{array}{c}\gamma-\mathrm{Al}_{2} \mathrm{O}_{3} / 3,0+ \\
\text { alumocalcite/ 3,0 }\end{array}$ & 2,42 & 2,50 & 2,60 & 2,62 & 45 \\
\hline 11 & $\begin{array}{c}\alpha-\mathrm{Al}_{2} \mathrm{O}_{3} / 5,0+ \\
\text { alumoalkaline / 3,0 }\end{array}$ & 2,34 & 2,41 & 2,43 & 2,52 & 47 \\
\hline 12 & $\begin{array}{c}\alpha-\mathrm{Al}_{2} \mathrm{O}_{3} / 5,0+ \\
\text { alumocalcite / 3,0 }\end{array}$ & 2,32 & 2,38 & 2,42 & 2,50 & 50 \\
\hline
\end{tabular}

\section{Discussion}

Table 2 shows that nanoadditives in portland cement compositions change structural parameters of materials on a nanolevel. All nanoadditives in the considered range of distances up to $80 \mathrm{~nm}$ reduce the average size of nanoparticles $\mathrm{C}-\mathrm{S}-\mathrm{H}$. In the specified range of distances scattering of neutrons happens on fractal surfaces. The increase of fractal dimension in the course of hydration indicates an increase in durability of a contact zone of $\mathrm{C}-\mathrm{S}-\mathrm{H}$ nanoparticles which are formed in the course of hydration of the portland cement.

The influence on structural parameters of the considered nanoadditives is bound not only to nanodimension of their particles. An important factor is the orientation of their impact on hydration process. Carbonate sludges, the nanopowders $\alpha-\mathrm{Al}_{2} \mathrm{O}_{3}$ and $\gamma-\mathrm{Al}_{2} \mathrm{O}_{3}$ have small reactivity. They are, most likely, considered to be filling nanoadditives. On the other hand, reactive alumoalkaline and alyumocalcite sludges are considered to be modifying nanoadditives. The experiments showed that the most perspective for application are the bipropellant (complex) nanoadditives consisting of the filling and modifying components.

\section{Conclusion}

Nanoadditives affect on structural parameters of hydrated portland cement compositions distribution of C-S-H nanoparticles by size, the average size of C-S-H nanoparticles, their fractal dimension. The application of the complex of filling and modifying nanoadditives allows to influence a targeted hydration process, thereby, operating process of formation of structural parameters of hydrated portland cement compositions and, finally, to influence properties of a cement stone.

The received dependences of values of structural parameters of portland cement compositions indicate the fact that the sludges used as additives, as well as nanopowders of $\alpha-\mathrm{Al}_{2} \mathrm{O}_{3}$ and $\gamma-\mathrm{Al}_{2} \mathrm{O}_{3}$ promote increase in durability of a contact zone of particles, increase 
in frost resistance, water resistance and rust resistance of a cement stone that will positively affect on longevity of structural cement composites.

\section{References}

1. J.W. Bullard, H.M. Jennings, R.A. Livingston, A. Nonat, G.W. Scherer, J.S. Schweitzer, K.L. Scrivener, J.J. Thomas, Cem. Concr. Res. 41, 1208 (2011)

2. A. Nonat, Cem. Concr. Res. 34, 1521 (2004)

3. L.B. Skinner, S.R. Chae, C.J. Benmore, H.R. Wenk, P.J.M. Monteiro, Phys. Rev. Let. 104, 195502 (2010)

4. L. Raki, J. Beaudoin, R. Alizadeh, J. Makar, T. Sato, Mater. 3, 918 (2010)

5. A.M. Guryanov, Proc. Engin. 111, 283 (2015)

6. A.M. Guryanov, Proc. Engin. 153, 217 (2016)

7. A. Guryanov, S. Korenkova, Yu. Sidorenko, MATEC Web of Conf. 86, 04011 (2016)

8. J.W. Phair, J.C. Schulz, W.K. Bertram, L.P. Aldridge, Cem. Concr. Res. 33, 1811 (2003)

9. J.J. Thomas, A.J. Allen, H.M. Jennings, Cem. Concr. Res. 42, 377 (2012)

10. W. Chiang, E. Fratini, F. Ridi, S. Lim, Y. Yeh, P.Baglioni, S. Choi, U. Jeng, S. Chen. J. Col. Interf. Science. 398, 67 (2013)

11. A. Trapote-Barreira, L. Porcar, J. Cama, J.M. Soler, A.J. Allen, Cem. Concr. Res. 72, $76(2015)$

12. S.F. Korenkova, T.V. Sheina, Bases and concept of utilization of chemical precipitation of the industrial drains in the construction industry (SGASU, Samara, 2004)

13. M.V. Avdeev, V.L. Akseonov, Phys. Usp. 53, 971 (2010)

14. J.J. Thomas, J.J. Chen, A.J. Allen, H.M. Jennings, Cem. Concr. Res. 34, 2297 (2004)

15. A.J. Allen, J.J. Thomas, H.M. Jennings, Nat. Mater. 6, 311 (2007)

16. A.J. Allen, J.J. Thomas, Cem. Concr. Res. 37, 319 (2007)

17. T. Ficker, Theor. Appl. Fract. Mech. 50,167 (2008)

18. Q. Zeng, M. Luo, X. Pang, L. Li, K. Li. Appl. Surf. Science. 282, 302 (2013)

19. Y. Gao, J. Jiang, G.D. Schutter, G. Ye, W. Sun, Const. Build. Mater. 69, 253 (2014)

20. P.V. Konarev, M.V. Petoukhov, V.V. Volkov, D.I. Svergun, J. Appl. Cryst. 39, 277 (2006)

21. M.V. Petoukhov, D. Franke, A.V. Shkumatov, G. Tria, A.G. Kikhney, M. Gajda, C. Gorba, H.D.T. Mertens, P.V. Konarev and D.I. Svergun, J. Appl. Cryst. 45, 342 (2012) 